\title{
The Temporal Organization Grid: A New Classification System of Temporary Organizations
}

\author{
Vallari Chandna ${ }^{1}$
}

With the increased recognition of the key role played by time in processes and outcomes, there has been a renewed focus on temporary organizations. Temporary organizational forms tend to receive attention due to certain characteristics that are unique to them, as compared to permanent organizations, with regard to issues like trust, communication, organizational structure, innovation and creativity among others. They have also been known to generate significant benefits for the organizations participating in them. But to study them in detail, a comprehensive classification system of temporary organizations is needed, which has so far been missing in the extant literature. This paper sets forth a classification grid for temporary organizations which is its primary purpose and also examines the different strategically important variables that further define the typological framework and that act as determinants of success of these temporary organizations.

Keywords: temporary organizations, new organizational types, teams, alliances, temporal

JEL classifications: $M 10,030$

\section{Introduction}

Organizations have been changing, evolving, and giving way to newer breeds of organizations including temporary organizations. Temporary organizations (TOs) have existed in different forms, shapes and under different guises and their importance has varied over time. While their temporariness is what makes them unique, it makes them harder to study and thus oft ignored. TOs have been known to generate significant benefits for the organizations participating in them (Albanese, 1994) and have certain unique characteristics as compared to permanent organizations, with regard to issues like trust (Meyerson et al. 1996),

${ }^{1} \mathrm{PhD}$. Assistant Professor of Management, Austin E. Cofrin School of Business, University of Wisconsin-Green Bay; 
communication (Katz, 1982), organizational structure (Juriado and Gustafsson, 2007), innovation (Blindenbach-Driessen and Van den Ende, 2006) and creativity (Skilton and Dooley, 2010) among others.

While the concept is not entirely new, there is no single definition of TOs in use. One of the earliest works was by Goodman and Goodman (1976) who defined "a temporary system" as "a set of diversely skilled people working together on a complex task over a limited period of time." Most recently, interorganizational TOs have been defined as groups of non-temporary organizations that collaborate towards accomplishing a joint task with an explicitly, pre-specified duration fixed either by specifying a date or defined by the completion of a task (Kenis, Janowicz-Panjaitan, \& Cambre, 2009). The terms temporary organizations, transient organizations, quasi-firm, temporary systems, have all been used interchangeably.

Essentially within TOs a group of people come together for a (relatively) short span of time, work diligently and then disperse, perhaps never to work with each other again -all the while maintaining the semblance of an "organization." There is however no comprehensive classification of TOs. Furthermore, strategically important variables which are crucial for TOs to have productive outcomes are under-explored. The motivation for this paper is thus to propose a new classification of TOs and examine the relevance of different strategic variables on the success of the different TOs.

\section{Temporal Organization Grid}

As far back as the sixties (Bennis, 1965; Miles, 1964), there was some hint to the concept coming into the literature of organizations. His focus was on the increased need for ad-hoc groups and the fact that changing environments necessitated the greater use of such temporary task forces. The focus thereafter was on creative TOs such as theatre productions (Goodman and Goodman, 1976) and film crews (Morley and Silver, 1977). Of the different forms of TOs that have begun to be explored more recently Bakker (2010) as mentioned has provided a comprehensive insight into research directions regarding TOs. A more comprehensive work addressing TOs as a whole and the research needs of the field has been done recently (Kenis et al., 2009). They discuss the need to explore the various variables that exist within TOs, whether they are determinants of success and whether they are applicable to TOs in general or certain specific kinds. This article heeds their call by exploring multiple strategic variables as determinants of success 
TOs have usually been studied within project-related frameworks (Jones and Lichenstein, 2004; Devine et al., 1999). A newer, more directly-related classification system is called for. To this end, the following classification is proposed:

\section{Temporal Organizational Grid}

\section{Table 1}

\begin{tabular}{|c|c|c|c|c|}
\hline \multirow{5}{*}{$\begin{array}{l}\text { Type of } \\
\text { Outcomes }\end{array}$} & & Within Firms (Wi) & Outside the firms (0) & Wholly Unique Entities (WUE) \\
\hline & Generation of Routine output (RO) & Trpe I & Trpe III & Trpe VI \\
\hline & & The Cockpit & The World Fair & The Jury \\
\hline & Creative solutions and innovative & Type II & Type IV & Type VI \\
\hline & output (CO) & The Think-Tank & The Alliance & The Film Crew \\
\hline
\end{tabular}

This $3 \times 2$ grid uses level of embeddedness in a firm and type of output desired as the two dimensions for classifying TOs. Organizations today are multifaceted housing complex group activities within the firms while also being involved in elaborate networks, alliances and projects with other firms or entities. Additionally they are certain unique enterprises that do not fall under either category. Thus, from an organizational perspective, all activities fall squarely under interfirm and intrafirm categories and thus this classifying dimension seems pertinent as it allows for interfirm, intrafirm and "extra-firm" categories.

For interfirm TOs, the members may come from multiple firms but some may belong to the same parent organization. In those TOs that are intrafirm all of the members come from the same parent/permanent organization. Unique entities i.e. those that come into existence as TOs from the outset, contain members not from a particular firm or firms but rather they usually consist of a multitude of unaffiliated individuals that have come together for the express purpose of being a part of a temporary organization.

The second dimension used for classification purposes is the type of desired output from the tasks performed by the organization. In her work on TOs, Bakker (2010) suggests a need for bringing in task uniqueness and organizational routines concepts into examining tasks involved in TOs. TOs similar to their permanent 
counterparts are tasked with having an end-product or an outcome. This varies depending on the purpose for which the group was created and thus falls into two subcategories (1) whether the output required is some sort of creative solution or is an innovative end product or result or (2) whether the output required at the end is a routine output.

Based on this method of classification, six types of TOs exist. All TOs would fall within one of these six types however, for the purpose of this paper; one example of each is highlighted as an archetype. The next step is to evaluate the various strategically relevant variables related to the TOs which lie in the Temporal Organization Grid. Thus, the aim is to not just classify TOs but take it one step further. Classification systems tend to merely categorize phenomena while typologies are more useful and theoretically rich. Accordingly using Doty and Glick's template (1994) of forming typologies, this paper sets forth a two dimensional, first-order construct for the classification of TOs and sets forth testable hypotheses regarding the various constructs that are falsifiable.

\section{The Strategic Variables}

The importance of successful goal attainment can be seen in the notion that generally most TOs are set up to accomplish one or more clearly defined goals and this is the reason for their existence (Lundin and Soderholm, 1995.) For the accomplishment of goals, the strategically significant variables that determine success need to be defined. These variables will differ for different types of TOs and should be explored in more detail (Kenis et al.,2009). To compare across TOs, strategic variables that are of the utmost importance to the successful functioning of organizations in general have been chosen. In the extant literature regarding TOs, these have been explored to some degree (Morley and Silver, 1977, Goodman and Goodman, 1976, Kenis et al., 2009 among others). These five strategic variables are: (1) knowledge and its codification, (2) innovation, (3) impact of external environment, (4) adaptive capabilities, and (5) resource dependency. 
Archetypes of Temporary Organizations and the Strategic Variables that are determinants of success for each type

Table 2

\begin{tabular}{|c|c|c|c|c|c|}
\hline \multirow{2}{*}{$\begin{array}{c}\text { Type of } \\
\text { TO - } \\
\text { Archetype } \\
\end{array}$} & \multicolumn{5}{|c|}{ Strategic Variables } \\
\hline & $\begin{array}{l}\text { Knowledge } \\
\text { codification }\end{array}$ & Innovation & $\begin{array}{l}\text { Resource } \\
\text { Dependency }\end{array}$ & $\begin{array}{l}\text { Impact of } \\
\text { external } \\
\text { environment }\end{array}$ & $\begin{array}{l}\text { Adaptive } \\
\text { capabilities }\end{array}$ \\
\hline $\begin{array}{l}\text { The } \\
\text { Cockpit }\end{array}$ & $\begin{array}{l}\text { High degrees } \\
\text { of } \\
\text { codification }\end{array}$ & $\begin{array}{l}\text { Not focused } \\
\text { on }\end{array}$ & $\begin{array}{l}\text { Low } \\
\text { importance- } \\
\text { dependent on } \\
\text { parent firm. }\end{array}$ & Unaffected & Not needed \\
\hline $\begin{array}{l}\text { The World } \\
\text { Fair }\end{array}$ & $\begin{array}{l}\text { Medium level } \\
\text { of } \\
\text { codification }\end{array}$ & $\begin{array}{l}\text { Not focused } \\
\text { on }\end{array}$ & Relevant & Affected & $\begin{array}{l}\text { Minimally } \\
\text { needed }\end{array}$ \\
\hline The Jury & $\begin{array}{l}\text { Low level of } \\
\text { codification }\end{array}$ & $\begin{array}{l}\text { Not focused } \\
\text { on }\end{array}$ & Relevant & Affected & Not needed \\
\hline $\begin{array}{l}\text { The } \\
\text { Think- } \\
\text { Tank }\end{array}$ & $\begin{array}{l}\text { Limited } \\
\text { codification }\end{array}$ & $\begin{array}{l}\text { Extremely } \\
\text { Important }\end{array}$ & $\begin{array}{l}\text { Low } \\
\text { importance- } \\
\text { dependent on } \\
\text { parent firm. }\end{array}$ & Unaffected & $\begin{array}{l}\text { Minimally } \\
\text { needed }\end{array}$ \\
\hline $\begin{array}{l}\text { The } \\
\text { Alliance }\end{array}$ & $\begin{array}{l}\text { Very limited } \\
\text { codification }\end{array}$ & $\begin{array}{l}\text { Extremely } \\
\text { Important }\end{array}$ & Relevant & $\begin{array}{l}\text { Highly } \\
\text { affected }\end{array}$ & $\begin{array}{l}\text { Minimally } \\
\text { needed }\end{array}$ \\
\hline $\begin{array}{l}\text { The Film } \\
\text { Crew }\end{array}$ & $\begin{array}{l}\text { Very limited } \\
\text { codification }\end{array}$ & $\begin{array}{l}\text { Extremely } \\
\text { Important }\end{array}$ & Highly relevant & Affected & Important. \\
\hline
\end{tabular}

Knowledge: Managing knowledge is key for organizational learning. Explicit knowledge or codified knowledge is the type of knowledge that can be integrated into the organizational knowledge system (Nonaka and von Krogh, 2009). While creation of knowledge does occur in TOs, not all rely on codified knowledge. Those with more routinized tasks and functions tend to have higher levels of codification while those directed towards creative output tend to exhibit limited codification (Teece, 1981). Knowledge transfer from, between and within TOs is particularly difficult (Lindner and Wald, 2011). Intrafirm TOs generally have access to the systematic processes of their firm and these processes help to transform the temporary knowledge obtained into more permanent knowledge by turning tacit knowledge into codified knowledge (Grant, 1996). Unique entities such as theatre productions will have an even lesser degree of codified knowledge; in such cases basic routines and steps to mount a production are codified but not 
much else; there is no method in place to extract any created knowledge which ends up remaining tacit (Goodman and Goodman, 1972). TOs geared towards producing routine output as a consequence of their routine tasks tend to be following standard operating procedures (Cyert and March 1993) which is codified knowledge. TOs that are geared towards producing a creative and innovative output will utilize different knowledge sharing mechanisms and their degree of codification of knowledge will be very limited (Boh 2007).

Innovation: Some TOs focus on innovation as part of their goals and desired outcomes. Innovation is chiefly related to the dimension "type of outcomes" on the Temporal Organization Grid. Thus, those where the output desired is routine, have no need to set in place processes for innovation or dedicate a large portion of their resources to it. Innovation, in this instance, takes a back seat to smooth operations and successfully fulfilling tasks to generate a standard, expected outcome. There has been a lot of research on the innovative capabilities of TOs and how they are more innovative than their permanent counterparts. This is one of the reasons why innovation is regarded as an important strategic variable with regard to TOs. Those TOs which are geared towards producing creative solutions and innovative output will clearly rank innovation as a very strong and relevant strategic variable as the primary reason for their existence is to produce an innovative output.

Impact of external environment: For all organizations the external environment in which it operates is an important variable. However, not all TOs are impacted equally by the external environment. Within the firm-type of TOs are fully contained within a single parent organization and their external environment would thus consist of their own firm and none of the traditional external environment factors. Outside of the firm-type of TOs on the other hand do not have this luxury and are affected by external environmental factors. The degree of this effect will vary depending on the type of temporary organization. Those TOs where the output is routine will be affected to a lesser degree than those whose output is innovative. This is because the impact of external environmental factors will not be as much of an unknown in case of routine outputs and routine activities and thus there won't be a large number of external environmental developments. TOs that come under the Wholly Unique Entity category will be affected to a higher degree by their external environment as they are operating independent of other firms without any protective buffers, as they are not part of a parent organization nor affiliated with one. 
Adaptive capabilities: TOs have time on their side and time against them. Adaptive capabilities are needed by some TOs to survive and then thrive but for other TOs, there is not enough time for utilizing any adaptive capabilities for the purposes of better functioning. The need for adaptive capabilities to respond to changes in the environment is well-established in the case of permanent organizations but it needs to be explored as it relates to TOs. In the case of intrafirm TOs, there is simply no need for adaptive capabilities as they are protected from the effects of external environmental factors. The need for adaptive capabilities, increases when outside of the firm TOs are considered due to the impact of external factors on them and their being less-isolated than other types of TOs. Those TOs that are wholly unique entities find themselves in a more vulnerable position when it comes to factors such as external environment and resource dependencies and will thus have a greater need for adaptive capabilities in the face of unforeseen changes. The other dimension of the Temporary Organizational Grid also helps understand the importance of adaptive capabilities. When the temporary organization is required to generate a creative or innovative output, the need for adaptive capabilities is certainly more likely given the need to engage in non-routine activities

Resource Dependency: Resources are of critical importance to TOs. Depending on their type TOs will be dependent on one or more organizations for their resource needs. In the case of TOs that are essentially within the firm in nature, the dependence will be on the parent organization itself. The temporary organization in this case is not a stand-alone unique entity nor is it related to multiple organizations. It is firmly connected to a single parent organization which is its source of origin and helps in its essential functioning. Thus, where the temporary organization is embedded within a permanent organization, it will be easier to manage the resource dependence (Lundin and Soderholm, 1995). Where the temporary organization is interfirm in nature, it will depend on one or more of its affiliated parent organizations in matters related to resources instead of being reliant on the environment for its resources. The resource dependence of outside of the firm TOs will be greater than within the firm, because there may not be clear lines of resource movement due to the multiple parent organizations involved. Unlike the other types of within the firm and outside of the firm TOs, wholly unique entity TOs do not have a group of parent firms or a single parent firm to turn to for their resource needs but operate instead within the general environment from which they draw their resources. Thus, generally speaking, TOs will tend to rely heavily on allocated resources over which they have little or no control. 
The postulates in this paper which are indicated by Table 2 are falsifiable in accordance with being part of a typology of temporary organizations (Doty and Glick, 1994) The need therefore is for them to be tested and proven right or their alternatives stated if there are not so.

\section{Conclusion}

The first purpose of this paper was to set forth the Temporal Organizational Grid which is first and foremost to act as a classification system of TOs. The Temporal Organizational Grid proposed here seeks to make a valuable contribution to the literature on the subject of TOs by providing the first comprehensive classification system of TOs as a whole. This is very different from the project classification and team classification literature in existence that has sometimes been resorted to as a crude substitute for a classification system of TOs. Empirical work on TOs has proved to be tricky in the past but that is where this classification system attempts to ease the problem and make it easier to study the particular forms of TOs and study them in better detail.

The second and equally important purpose of this paper was to use the classification system to create a typology of TOs based on the strategically significant variables. While the two dimensions of the Temporal Organizational Grid i.e. level of embeddedness in a firm and type of desired output, help us determine where a temporary organization fits in, the five important strategic variables help us clearly see the theoretical aspects relating to those TOs and answer questions like which types will value innovation? Are all types of TOs equally concerned about resource allocation? Is the external environment relevant to TOs as we understand them? This paper answers these and other questions relating to strategic variables through the proposed typology.

\section{References}

Albanese, R. (1994) "Team-Building Process: Key to Better Project Results", Journal of Management in Engineering, Vol. 10 No. 6, pp. 36-44.

Bakker, R. (2010) "Taking Stock of Temporary Organizational Forms: A Systematic Review and Research Agenda", International Journal of Management Reviews, Vol. 12 No. 4, pp. 466-486.

Bennis, W. (1965) "Beyond bureaucracy", Society, Vol. 2 No. 5, pp. 31-35.

Blindenbach-Driessen, F. and van den Ende, J. (2006), "Innovation in projectbased firms: The context dependency of success factors", Research Policy, Vol. 35 No. 4, pp. 545-561. 
Boh, W. (2007) "Mechanisms for sharing knowledge in project-based organizations", Information and Organization, Vol. 17 No. 1, pp. 27-58.

Cyert, R.M. and March, J.G. (1963) A behavioral theory of the firm. NJ: Englewood Cliffs.

Devine, D.J., Clayton, L.D., Philips, J.L., Dunford, B.B. and S.B. Melner (1999) "Teams in organizations: Prevalence, characteristics, and effectiveness", Small Group Research, Vol. 30 No. 6, pp. 678-711.

Doty, D. and Glick, W. (1994) "Typologies as a Unique Form of Theory Building: Toward Improved Understanding and Modeling", The Academy of Management Review, Vol. 19 No. 2, p. 230.

Goodman, L. and Goodman, R. (1972) "Theater as a Temporary System", California Management Review, Vol. 15 No. 2, pp. 103-108.

Goodman, R. and Goodman, L. (1976) "Some Management Issues in Temporary Systems: A Study of Professional Development and Manpower-The Theater Case", Administrative Science Quarterly, Vol. 21 No. 3, p. 494.

Grant, R. (1996) "Toward a knowledge-based theory of the firm", Strategic Management Journal, Vol. 17 No. S2, pp. 109-122.

Jones, C. and Lichtenstein, B.B. (2008) "Temporary interorganizational projects: How temporal and social embeddedness enhance coordination and manage uncertainty", in Oxford Handbook of Interorganizational Relationships, Oxford, UK: Oxford University Press

Juriado, R. and Gustafsson, N. (2007) "Emergent communities of practice in temporary inter-organisational partnerships", The Learning Organization, Vol. 14 No. 1, pp. 50-61.

Katz, R. (1982) "The Effects of Group Longevity on Project Communication and Performance", Administrative Science Quarterly, Vol. 27 No. 1, p. 81.

Kenis, P., Janowicz-Panjaitan, M.K., Cambré, B. (2009) Temporary Organizations: Prevalence, Logic and Effectiveness. Cheltenham: Edward Elgar.

Lindner, F. and Wald, A. (2011) "Success factors of knowledge management in temporary organizations", International Journal of Project Management, Vol. 29, No. 7, pp. 877-888.

Lundin, R. and Söderholm, A. (1995) "A theory of the temporary organization", Scandinavian Journal of Management, Vol. 11 No. 4, pp. 437-455.

Meyerson, D., Weick, K.E. and Kramer, R.M. (1996) "Swift trust and temporary groups", in Kramer, R.M. and Tyler, T.R. (ed.), Trust in Organizations: Frontiers of Theory and Research, Thousand Oaks, CA: Sage

Miles, M.B. (1964) "On temporary systems", in Miles, M.B. (ed), Innovation in Education, New York: Teachers College, Columbia University. 
Morley, E. and Silver, A. (1977) "A film director's approach to managing creativity", Harvard Business Review, Vol 55, pp. 59-70.

Nonaka, I. and von Krogh, G. (2009) "Perspective-Tacit Knowledge and Knowledge Conversion: Controversy and Advancement in Organizational Knowledge Creation Theory", Organization Science, Vol. 20 No. 3, pp. 635-652.

Skilton, P. and Dolley, K. (2010) "The Effects of Repeat Collaboration on Creative Abrasion", Academy of Management Review, Vol. 35 No. 1, pp. 118-134.

Teece, D. (1981) "The Market for Know-How and the Efficient International Transfer of Technology", The Annals of the American Academy of Political and Social Science, Vol. 458 No. 1, pp. 81-96. 